\title{
Magnetic Nanoparticle-Based Biosensing Assay Quantitatively Enhances Acid-Fast Bacilli Count in Paucibacillary Pulmonary Tuberculosis
}

\author{
Cristina Gordillo-Marroquín 1,2,3 , Anaximandro Gómez-Velasco 1,2,3, \\ Héctor J. Sánchez-Pérez ${ }^{1,2,3}{ }^{1}$, Kasey Pryg ${ }^{4}$, John Shinners ${ }^{4}$, Nathan Murray ${ }^{4}$, \\ Sergio G. Muñoz-Jiménez ${ }^{3,5}$, Allied Bencomo-Alerm ${ }^{3,5}$, Adriana Gómez-Bustamante ${ }^{6}$, \\ Letisia Jonapá-Gómez ${ }^{6}$, Natán Enríquez-Ríos ${ }^{3,7}$, Miguel Martín ${ }^{2,8}$, \\ Natalia Romero-Sandoval ${ }^{2,9}$ (D) and Evangelyn C. Alocilja ${ }^{3,4, *}$ \\ 1 Health Department, El Colegio de la Frontera Sur (ECOSUR), San Cristobal de Las Casas, Chiapas 29290, \\ Mexico; naabani@gmail.com (C.G.-M.); agv23@yahoo.com (A.G.-V.); hsanchez@ecosur.mx (H.J.S.-P.) \\ 2 The Network GRAAL (Grups de Recerca d'America i Africa Llatines)-ECOSUR Node, San Cristobal de Las \\ Casas, Chiapas 29290, Mexico; Miquel.Martin@uab.es (M.M.); nromero@internacional.edu.ec (N.R.-S.) \\ 3 Global Alliance for Rapid Diagnostics. Michigan State University, East Lansing, MI 48824, USA; \\ giuseppemj@gmail.com (S.G.M.-J.); alliedbgraal@gmail.com (A.B.-A.); ernatan@gmail.com (N.E.-R.) \\ 4 Nano-Biosensors Laboratory, Department of Biosystems and Agricultural Engineering, Michigan State \\ University, East Lansing, MI 48824, USA; kpryg22@gmail.com (K.P.); shinner1@msu.edu (J.S.); \\ nathan.h.murray@gmail.com (N.M.) \\ 5 Mycobacteriology Laboratory, TB Prevention and Control Program for the Highlands of Chiapas, \\ Chiapas 29250, Mexico \\ 6 State Public Health Laboratory for Chiapas, Tuxtla Gutierrez, Chiapas 29040, Mexico; \\ adrgomezb73@hotmail.com (A.G.-B.); letisiajgo@hotmail.com (L.J.-G.) \\ 7 Communicable and Non-communicable Diseases Department, Ministry of Health of Chiapas, Tuxtla \\ Gutierrez, Chiapas 29010, Mexico \\ 8 Biostatistics and Epidemiology Unit, Autonomous University of Barcelona, 08193 Bellaterra, Spain \\ 9 Faculty of Medical Sciences, and Health and Life, International University of Ecuador, \\ Quito 170113, Ecuador \\ * Correspondence: alocilja@msu.edu; Tel.: +1-517-432-8672
}

Received: 30 October 2018; Accepted: 9 December 2018; Published: 12 December 2018

\begin{abstract}
A new method using a magnetic nanoparticle-based colorimetric biosensing assay (NCBA) was compared with sputum smear microscopy (SSM) for the detection of pulmonary tuberculosis (PTB) in sputum samples. Studies were made to compare the NCBA against SSM using sputum samples collected from PTB patients prior to receiving treatment. Experiments were also conducted to determine the appropriate concentration of glycan-functionalized magnetic nanoparticles (GMNP) used in the NCBA and to evaluate the optimal digestion/decontamination solution to increase the extraction, concentration and detection of acid-fast bacilli (AFB). The optimized NCBA consisted of a 1:1 mixture of $0.4 \% \mathrm{NaOH}$ and $4 \% \mathrm{~N}$-acetyl-L-cysteine (NALC) to homogenize the sputum sample. Additionally, $10 \mathrm{mg} / \mathrm{mL}$ of GMNP was added to isolate and concentrate the AFB. All TB positive sputum samples were identified with an increased AFB count of $47 \%$ compared to SSM, demonstrating GMNP's ability to extract and concentrate AFB. Results showed that NCBA increased AFB count compared to SSM, improving the grade from " $1+$ " (in SSM) to " $2+$ ". Extending the finding to paucibacillary cases, there is the likelihood of a "scant" grade to become " $1+$ ". The assay uses a simple magnet and only costs $\$ 0.10 /$ test. NCBA has great potential application in TB control programs.
\end{abstract}

Keywords: Mycobacterium tuberculosis; increased sensitivity; sputum smear microscopy; TB detection; nanotechnology; infectious disease 


\section{Introduction}

One third of the world's population carries an asymptomatic infection from Mycobacterium tuberculosis $(M t b)$. In 2017, 10.4 million people fell ill with tuberculosis (TB), and 1.6 million died from the disease (including 0.4 million among people with HIV) [1]. Cost, technical limitations and lack of resources make the diagnosis of TB difficult in developing countries, where the majority of cases occur.

The primary method to diagnose TB in most low and middle income countries is sputum smear microscopy (SSM), using the Ziehl-Neelsen (ZN) staining technique [2]. SSM is highly specific for $M t b$ and can identify the most infectious patients in areas where there is a high TB prevalence [2]. Although this test is easy to perform, inexpensive, provides rapid results and does not require complex laboratory equipment, it has considerable drawbacks [3]. The clinical sensitivity of this test is highly variable (20-80\%) with much lower sensitivity in paucibacillary cases, such as in immunocompromised or pediatric patients where the bacterial load is usually fewer than 5,000-10,000 acid-fast bacilli (AFB) per milliliter of sputum sample [2-4].

The World Health Organization endorses the Xpert MTB/RIF (Cepheid, Sunnyvale, CA, USA) real-time PCR platform to diagnose $\mathrm{TB}$, primarily because it can identify rifampicin resistance in a short amount of time (120 min) [5]. However, its use is limited due to the high cost (instrument, cartridges and laboratory requirements) [6]. Additionally, reports have indicated that it can provide false-positive results [7,8].

Recent advances in nanotechnology have enabled the development of new diagnostic platforms aimed at more sensitive and faster pathogen detection [9-14]. However, they are designed for operation in environments with fully supported infrastructure [10-14]. Simple and low-cost nanotechnology-based TB diagnostics are still needed, where there is demand for a TB diagnostic that is suitable for low-resource clinical settings and that can be easily integrated into clinical practice.

This paper reports the use of a glycan-functionalized magnetic nanoparticle-based colorimetric biosensing assay (NCBA) that can be used to capture and increase the AFB count in PTB positive sputum samples without the use of expensive and temperature-sensitive antibodies. The advantages of the assay include: (1) Room-temperature assay, (2) no need for a power supply, (3) no refrigeration, (4) affordable (\$0.10/test), (5) rapid (<20 min), and (6) simple to implement. Using only a simple magnet, the glycan-functionalized magnetic nanoparticles (GMNPs) function as an extractor and concentrator of AFB without the need for an electrically powered centrifuge. No antibodies, aptamers or peptides are required. Once the GMNP-AFB complex is formed, GMNPs facilitate rapid detection due to the presence of visually observable clumped red-stained bacilli which are surrounded by brown nanoparticles. This technique could be easily integrated into conventional TB control programs in any resource-limited setting and where SSM has low sensitivity performance [15-23]. The assay relies on the physical (magnetic) and chemical (glycan) properties of the nanoparticles to concentrate mycobacteria cells from clinical samples. The acid-fast property of mycobacterial cells allow the color change from gray to red. Specifically, acid-fastness is a staining property shared by mycobacterial species which possess on their cell wall surface the presence of complex branched-chain hydroxy lipids termed mycolic acids, or mycolates. In the acid-fast stain, the carboxylic acid group of the mycolic acid reacts with the fuchsin dye. Subsequent application of a decolorizer will remove fuchsin from the cell walls of non-mycobacteria, but not in mycobacteria. Thus, red clumps surrounded by brown particles would indicate the presence of a mycobacterial species, hence the name "nanoparticle-based colorimetric biosensing assay" (NCBA).

\section{Materials and Methods}

\subsection{Chemicals and Reagents}

N-acetyl-L-cysteine (NALC) and sodium hydroxide $(\mathrm{NaOH})$ were purchased from Sigma-Aldrich (St. Louis, MO, USA). The NaOH (0.4\%) and NALC $(0.025 \%, 1 \%, 2 \%$ and $4 \%)$ were prepared in distilled water. A phosphate buffer saline solution (0.01 M PBS) was prepared using standard protocols. Carbol 
fuchsin, $0.3 \%$, was prepared by dissolving $50 \mathrm{~g}$ of phenol in $100 \mathrm{~mL} 90 \%$ ethanol and adding $3 \mathrm{~g}$ of basic fuchsin in the mixture which was brought to $1 \mathrm{~L}$ by adding distilled water. The decolorization solution was $25 \%$ sulphuric acid. The counter stain was $0.3 \%$ methylene blue. GMNPs were provided by the Alocilja Research Group from Michigan State University (USA). Briefly, GMNP (100 $\pm 58 \mathrm{~nm}$ ) has a magnetite $\left(\mathrm{Fe}_{3} \mathrm{O}_{4}\right)$ core and a glycan (chitosan) coating. $\mathrm{Fe}_{3} \mathrm{O}_{4}$ was synthesized using ferric chloride hexahydrate $\left(\mathrm{FeCl}_{3} \cdot 6 \mathrm{H}_{2} \mathrm{O}\right)$ as a precursor in a mixture of ethylene glycol (as a reducing agent) and sodium acetate (as a porogen). Chitosan was polymerized to surface-modify the iron oxide nanoparticles.

\subsection{Clinical Samples}

Twenty-four left-over sputum samples collected from an equal number of patients diagnosed with PTB were used, collected from the Mycobacteriology Laboratory, TB Prevention and Control Program for the Highlands region of Chiapas, Mexico (Ministry of Health). Sputum samples (at least $1 \mathrm{~mL}$ ) were used prior to the initiation of the anti-TB therapy. All information relating to the patients was removed and the samples were decoded prior to their handling and processing. The samples were either processed immediately on arrival at the laboratory or stored for less than $24 \mathrm{~h}$ at $4{ }^{\circ} \mathrm{C}$ before processing. The samples were weighed with the assumption that $1 \mathrm{~g}$ equals $1 \mathrm{~mL}$.

\subsection{Optimization of Digestion Reagent}

Twelve of the 24 sputum samples were used to optimize digestion-decontamination. Various concentrations of $\mathrm{NaOH}$ and NALC were evaluated to liquefy and homogenize the samples without negatively affecting the extraction ability of GMNP. Based on previous studies in the lab (unpublished data), $0.4 \% \mathrm{NaOH}$ was optimum and was used with different concentrations of NALC $(0.025-4 \%)$ in a 1:1 ratio to liquefy and homogenize the samples. The digestion time was monitored.

\subsection{NCBA versus SSM}

The NCBA approach was compared with the SSM method. Liquefied sputum samples were separated into two portions, one for SSM and the other for the NCBA experiments. Figure 1 shows a schematic of the SSM and NCBA approaches. The NCBA approach has two additional steps compared with SSM: The addition of GMNP to the liquefied sputum sample and magnetic separation. Unless GMNP concentration was the variable, $10 \mathrm{mg} / \mathrm{mL}$ of GMNP was used.

\subsection{Sputum Smear Microscopy (SSM)}

A smear was prepared from the first portion of the sample using the SSM method following the standard protocol [3,24]. Briefly, $20 \mu \mathrm{L}$ of the sputum sample was placed on a microscope slide $\left(\sim 400 \mathrm{~mm}^{2}\right)$ and heat fixed by passing flame from a Bunsen burner under the slide. The slide was then placed on a staining rack and $0.3 \%$ carbol-fuchsin was poured over the smear. The underside of the slide was gently heated by passing a flame under the rack until fumes appeared. After cooling ( $\sim 2 \mathrm{~min}$ ), the smear was rinsed with distilled water until no color appeared in the effluent, followed by washing with $25 \%$ sulphuric acid several times until the smear appeared light pink. The smear was washed with distilled water and then $0.3 \%$ methylene blue was added to cover the smear. Distilled water was used to wash off the counter stain and then the smear was air-dried. Once ready, the smear was examined under a bright field microscope (Eclipse E400, Nikon Instruments Inc., NY, USA) using a $100 \times$ oil immersion objective to observe the presence of red-colored AFB. 
Conventional AFB Smear Microscopy (SSM)

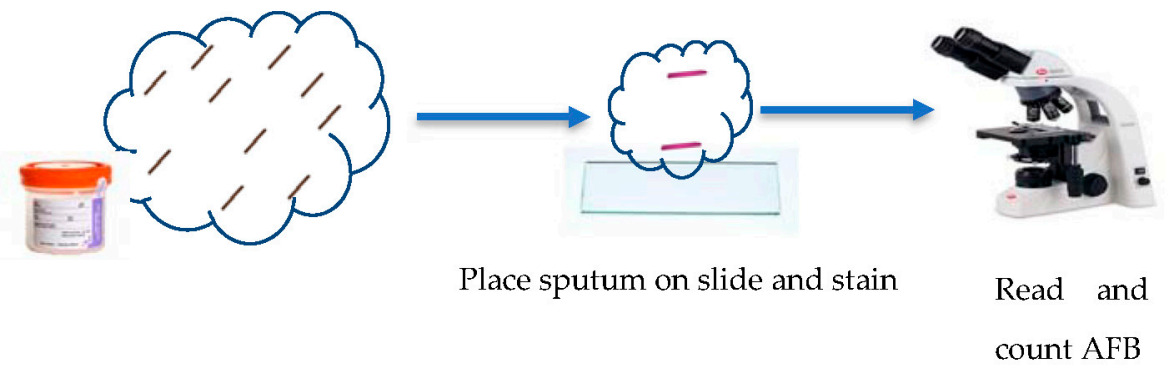

Nanoparticle-based Colorimetric Biosensing Assay (NCBA)

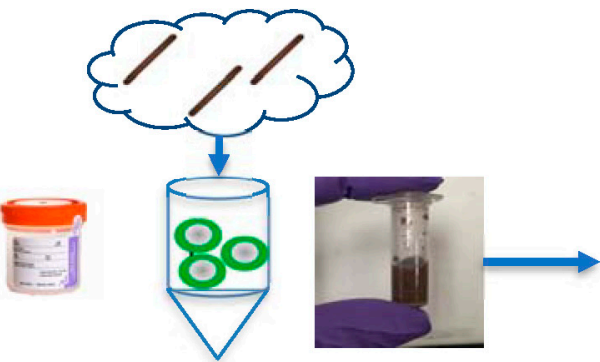

$\underline{\text { Step } 1}$

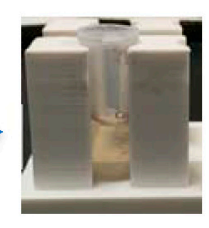

$\underline{\text { Step } 2}$

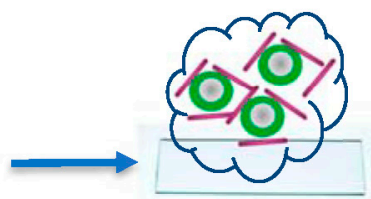

$\underline{\text { Step } 3}$
Add sputum to GMNP tube, shake, let stand 5 min
Place tube on magnetic rack, remove supernatant
Place GMNP-AFB

on slide and stain

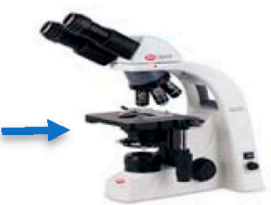

Read and count AFB

Figure 1. Schematic representation of sputum smear microscopy (SSM) (top) and nanoparticle-based colorimetric biosensing assay (NCBA) (bottom) approaches.

\subsection{NCBA Approach}

About $1 \mathrm{~mL}$ of the second portion of the sample was added into a $1.5 \mathrm{~mL}$ tube containing 0.5 $\mathrm{mL}$ of GMNP solution. The GMNP and sputum were mixed and allowed to incubate for $10 \mathrm{~min}$ at room temperature. The tube was then placed in a magnetic rack to separate the magnetic GMNP-AFB complex and the supernatant was discarded. The GMNP-AFB complexes were then washed and re-suspended in $0.5 \mathrm{~mL}$ of $0.01 \mathrm{M}$ PBS. A smear was prepared by transferring $20 \mu \mathrm{L}$ of the liquefied sputum sample onto a microscope slide which was processed similar to the SSM method, where it was then examined under a bright field microscope to observe the presence of any clumped red-colored AFB surrounded by brown nanoparticles.

\subsection{Optimization of GMNP Concentration}

In nine out of the 24 sputum samples, GMNP was added at three different concentrations $(0.5,10$, and $20 \mathrm{mg} / \mathrm{mL}$ ) to determine the best concentration for the capture, extraction, concentration and detection of AFB in the sputum samples. The subsequent procedure followed the NCBA approach which was described above. To homogenize the sputum sample, $0.4 \% \mathrm{NaOH} / 1 \%$ NALC was added. The time for magnetic separation was also determined.

\subsection{Validation of the Optimized Parameters}

Based on the optimization results, the remaining three of the 24 samples were used to validate $0.4 \% \mathrm{NaOH} / 4 \% \mathrm{NALC}$ for digestion and $10 \mathrm{mg} / \mathrm{ml} \mathrm{GMNP}$ for extraction.

\subsection{Quantification of the AFB Count}

The slides were mounted on a bright field optical microscope (Nikon Eclipse E400 Instruments Inc.) and examined under oil immersion $(100 \times)$. One hundred microscopy fields were observed to quantify 
the number of AFB present in each slide, for both SSM and NCBA, and all samples per treatment of $\mathrm{NaOH} / \mathrm{NALC}$ were pooled for reporting and statistical analysis.

\subsection{Data Analysis}

Statistical analysis was performed using SPSS version 21 on pooled data for each treatment, AFB counts per field and the total number of fields. Pair-wise student's t-tests were performed to compare AFB mean counts between SSM and NCBA, in determining the digestion-homogenization treatment and the optimal GMNP concentration. Pearson's correlation coefficient was determined to evaluate the association between the time for homogenization and magnetic separation. To measure the effect of the length of time for homogenization and magnetic separation on the number of AFB observed in NCBA, a linear regression model was used. All analyses were calculated at a $95 \%$ confidence interval $(\alpha=0.05)$.

\subsection{Capture Efficiency (CE) of GMNP for Mycobacterial Cells}

To understand the dynamics of GMNP-AFB interaction, a supplemental study was conducted to determine the CE of GMNP for mycobacteria. Based on previous preliminary studies (unpublished data), $5 \mathrm{mg} / \mathrm{mL}$ of GMNP was used. Due to biosafety considerations, Mycobacterium smegmatis (Msm) was used as a surrogate for $M t b$ in the CE experiments. Msm shares a similar cell wall structure with $M t b$, both are AFB species, and both can be stained using the $\mathrm{ZN}$ technique $[25,26]$. Artificial sputum was prepared following the polyacrylamide-based artificial sputum method [27]. A Msm culture was grown in a MiddleBrook 7H9-ADC broth and incubated until the optical density reached 0.6 at $600 \mathrm{~nm}$ (about log phase). Serial dilutions of the $M s m$ bacteria were prepared and spiked into the artificial sputum, followed by incubation for $10 \mathrm{~min}$ at room temperature along with manual shaking. The GMNP-Msm complexes were magnetically separated using a simple magnetic rack and the supernatant was removed. The complexes were washed twice and re-suspended in $0.5 \mathrm{~mL}$ of $0.01 \mathrm{M}$ PBS. The separated complexes along with pure bacterial dilutions were plated on a MiddleBrook 7H10-ADC agar and incubated for seven days to allow the growth of Msm cells. The CE was determined as the logarithm of cells captured divided by the logarithm of cells in the original dilution, as in Equation (1):

$$
C E=\frac{\log (\text { cell count of cells captured })}{\log (\text { cell count of cells in original dilution })}
$$

\subsection{Transmission Electron Microscope (TEM) Imaging}

GMNP-Msm complexes captured according to the previous section were visualized using a JEOL 100 CX transmission electron microscopy (TEM) at the MSU Center for Advanced Microscopy with a magnification range of $5000 \times$ to $80,000 \times$.

\subsection{Ethics}

Human subjects: Informed consent for participation was obtained from the patients and ethical approval was obtained from the Research Committee at ECOSUR (CEI-O-47/14) as well as from the Ministry of Health for Chiapas (5003/5342), under the project "Testing and evaluating a low-cost, field-operable biosensor for rapid detection of pulmonary tuberculosis". Sputum samples were used only for the purpose of this study and the remaining samples were disposed according to biosafety guidelines.

\section{Results}

\subsection{Effect of NaOH-NALC Treatments on AFB Count}

The role of $\mathrm{NaOH}$ is to eliminate the normal upper respiratory tract flora and the role of NALC is to break down the disulfide bonds in mucin so that the sputum is liquefied and the AFB are released 
during the assay. The AFB count using NCBA increased to 35\% with $1 \%$ NALC, followed by $22 \%$ with $2 \%$ NALC, and finally by $143 \%$ with $4 \%$ NALC $(1216,9353$, and 7682 , respectively, Table 1$)$ for the same number of fields counted compared to SSM $(903,7677$, and 3160, respectively) for pooled data of 300 fields for each treatment (three samples per treatment, total of 12 samples). NALC at $4 \%$ produced the highest AFB count.

Table 1. Optimization of N-acetyl-L-cysteine (NALC) treatment.

\begin{tabular}{ccccc}
\hline Concentration of NALC Solution & Number of AFB by SSM & Number of AFB by NCBA & No. Fields Observed & \% Increase (NCBA-SSM) \\
\hline $0.025 \%$ & 6525 & 3958 & 300 & $-39 \%$ \\
$1 \%$ & 903 & 1216 & 300 & $35 \%$ \\
$2 \%$ & 7677 & 9353 & 300 & $22 \%$ \\
$4 \%$ & 3160 & 7682 & 300 & $143 \%$ \\
\hline
\end{tabular}

Abbreviations: AFB, acid-fast bacilli; SSM, sputum smear microscopy; NCBA, nanoparticle-based colorimetric biosensing assay.

\subsection{Effect of GMNP Concentration on AFB Count}

For the samples tested, GMNP at $10 \mathrm{mg} / \mathrm{mL}$ was the best concentration, with an AFB count

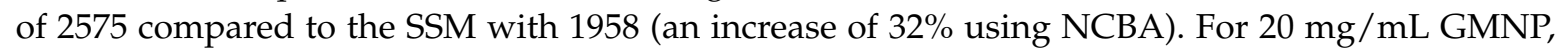
significant agglomerations were observed on the smear slides that affected the ability to clearly count the cells. GMNP at $0.5 \mathrm{mg} / \mathrm{mL}$ had a negative effect on the AFB count for NCBA, potentially due to reduced magnetic extraction effect while increasing the drag factor (Table 2).

Table 2. Optimization of the glycan-functionalized magnetic nanoparticles (GMNP) concentration.

\begin{tabular}{ccccc}
\hline Concentration of GMNP & Number of AFB by SSM & Number of AFB by NCBA & No. Fields Observed & \% Increase (NCBA-SSM) \\
\hline $0.5 \mathrm{mg} / \mathrm{mL}$ MNP & 876 & 391 & 300 & $-55 \%$ \\
$10 \mathrm{mg} / \mathrm{mL}$ MNP & 1958 & 2575 & 300 & $32 \%$ \\
$20 \mathrm{mg} / \mathrm{mL}$ MNP & 3979 & 5169 & 300 & $30 \%$ \\
\hline
\end{tabular}

Abbreviations: AFB, acid-fast bacilli; SSM, sputum smear microscopy; NCBA, nanoparticle-based colorimetric biosensing assay.

\subsection{Validation of the Optimized Parameters}

Based on the optimization results (Tables 1 and 2), the optimized treatment was $0.4 \% \mathrm{NaOH} / 4 \%$ NALC in a 1:1 ratio and $10 \mathrm{mg} / \mathrm{mL}$ of GMNP. Figure 2 shows that by using the optimized parameters, the AFB count for SSM was 4059 and NCBA was 5977, increasing NCBA by $47 \%$, showing the extraction and concentration effect. The clinical relevance of this result is that an AFB count below 5000 in SSM would be considered a paucibacillary case and would likely lead to a false negative result in conventional settings, increasing the risk of TB transmission. With NCBA, the AFB count is close to 6000 , increasing the chance of a positive result and getting treatment, thus minimizing transmission while increasing TB control. 


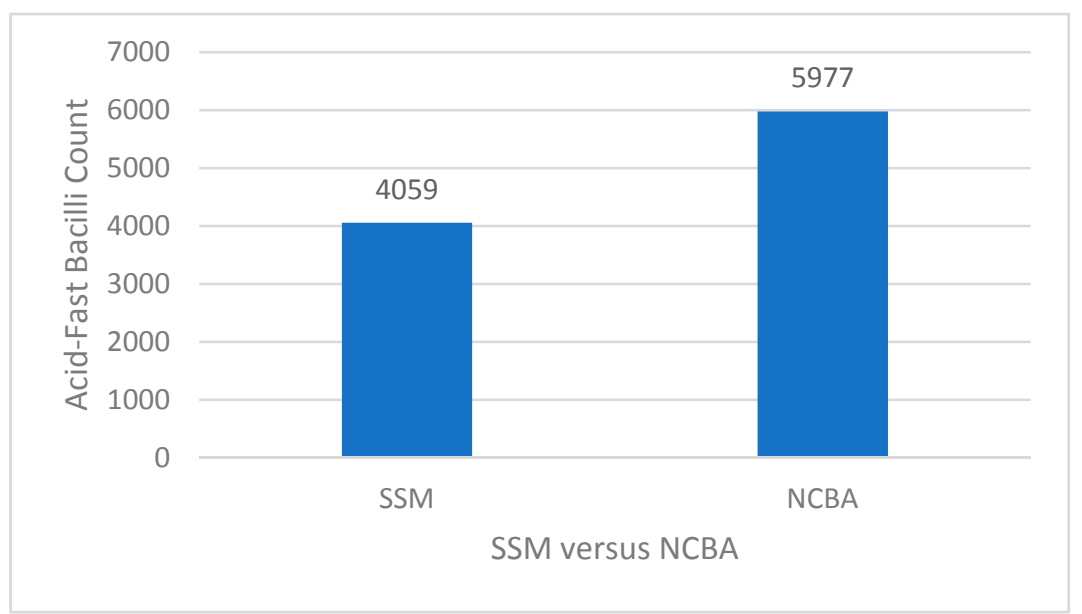

Figure 2. Results of the optimized parameters using $0.4 \% \mathrm{NaOH} / 4 \% \mathrm{NALC}$ and $10 \mathrm{mg} / \mathrm{mL}$ glycan-functionalized magnetic nanoparticles (GMNP), with NCBA increasing AFB count by $47 \%$ compared to SSM.

\subsection{Effect of NCBA in Grading Smears}

Each of the 24 samples was graded according to standard guidelines by a trained microscopist: Seven were graded as $1+$ and 17 were graded as $3+$ (Table 3 ). The pooled AFB count for $1+$ was 685 and 977 for SSM and NCBA, respectively, showing a gain of $43 \%$ by NCBA. The pooled AFB count for $3+$ was 28,504 and 35,344 for SSM and NCBA, respectively, showing a gain of $24 \%$ by NCBA. Table 3 shows that $1+$ would upgrade to $2+$ using the NCBA. The equivalent AFB count per mL $(20 \mu \mathrm{L}$ of sample on 100 fields) was calculated and is also presented in Table 3. This result is impactful as there are many clinical cases of low bacillary counts (paucibacillary).

Table 3. Acid-fast bacilli (AFB) count analysis of the graded samples.

\begin{tabular}{|c|c|c|c|}
\hline & $1+$ Grade $^{a}$ & $2+$ Grade $^{a}$ & 3+ Grade ${ }^{a}$ \\
\hline SSM, Total AFB counts & 685 & & 28,504 \\
\hline NCBA, Total AFB counts & 977 & & 35,344 \\
\hline No. Fields & 700 & & 1700 \\
\hline Percent increase by NCBA & $43 \%$ & & $24 \%$ \\
\hline SSM, AFB per $100 \mathrm{HPF}$ & 98 & & 1677 \\
\hline NCBA, AFB per $100 \mathrm{HPF}$ & 140 & 140 & 2079 \\
\hline $\mathrm{SSM}, \mathrm{AFB} / \mathrm{mL}$ & $4.9 \times 10^{3}$ & & $8.4 \times 10^{4}$ \\
\hline NCBA, AFB/mL & $7.0 \times 10^{3}$ & & $1.0 \times 10^{5}$ \\
\hline
\end{tabular}

Abbreviations: SSM, sputum smear microscopy; NCBA, nanoparticle-based colorimetric biosensing assay; $\mathrm{HPF}$, high power fields. ${ }^{a}$ Based on WHO and IUATLD grading scale: Negative (0 AFB/100 HPF); Scanty (1-9 AFB/100 HPF); 1+ (10-99 AFB/100 HPF); 2+ (100-9900 AFB/100 HPF on average); 3+ (>10,000 AFB/100 HPF on average).

Figure 3 shows images of stained AFB slides for SSM and NCBA on sputum samples graded as $1+, 2+$, and $3+$, according to the guidelines by the WHO and IUATLD [24]. There is an obvious concentration effect using NCBA (Figure 3A) compared with SSM (Figure 3B) and also a higher AFB count in NCBA, compared to SSM. In some fields, the number of AFB observed in NCBA were highly clustered. 
$1+$

A

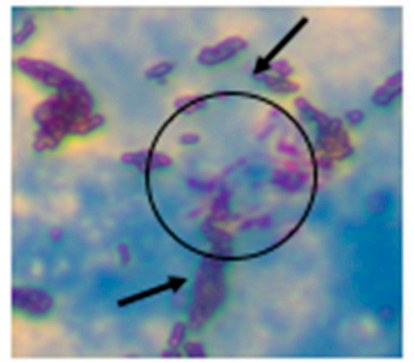

B

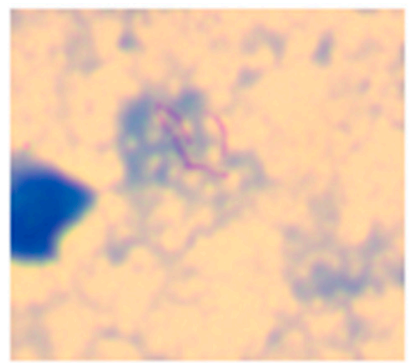

$2+$
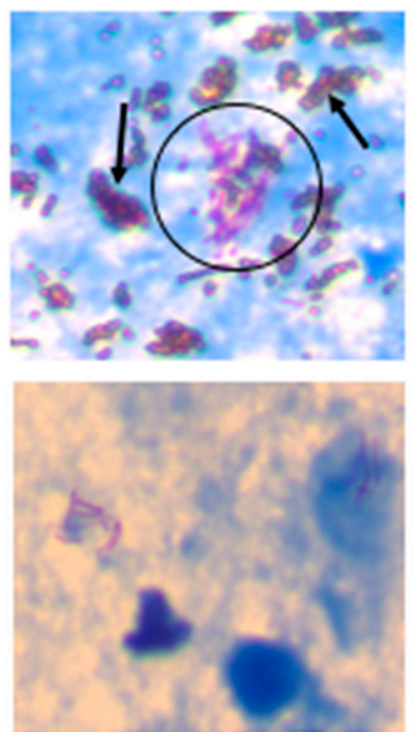

$3+$
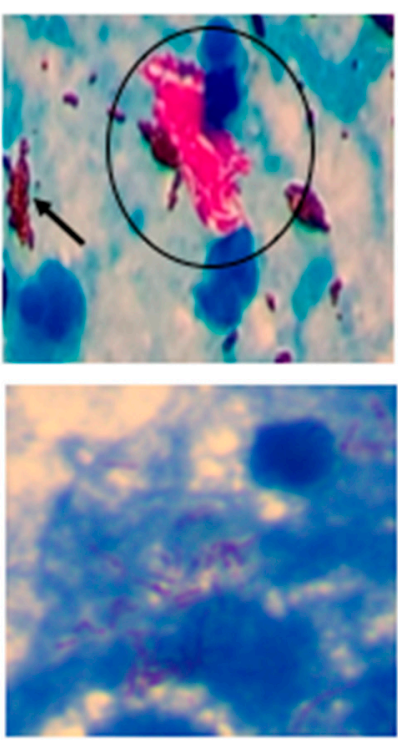

Figure 3. Images of AFB cells on smear slides for NCBA (A) and SSM (B). AFB appear dark red, surrounded by brown nanoparticles in NCBA. Representative images of sputum samples graded as $1+, 2+$, and $3+$ are shown. There is an obvious agglomeration of GMNP-AFB in the NCBA. The blue background comes from the methylene blue that is added during the assay to decolorize non-mycobacterial cells.

SSM positivity and grade indicate relative bacterial load, associated disease presentation, and infectivity for patients with TB according to the guidelines by the International Union Against Tuberculosis and Lung Disease (IUATLD) and the World Health Organization (WHO). The grade is either $3+, 2+, 1+$, scanty or negative, according to the number of AFB present in one hundred microscopic fields. A single sputum sample must have between $5000-10,000$ cells per $\mathrm{mL}$ for reliable TB detection; below this concentration, SSM might give either negative or uncertain result.

\subsection{Effect of Homogenization and Magnetic Separation on AFB Count}

Statistical analyses were conducted to assess whether the sample volume, time for homogenization and time for magnetic separation influenced AFB count in the NCBA. The results showed that there was no association between the sample volume and the mean time of homogenization (Pearson's correlation, $-0.016 ; p=0.42)$, implying that sample volume did not affect homogenization time. However, the mean time for homogenization and magnetic separation were correlated (Pearson's correlation, 0.643; $p<0.001)$. The longer it took to homogenize the sample, the more time was needed to magnetically separate the GMNP-AFB complex from the rest of the sputum matrix. It was also found that a longer period of homogenization resulted in higher AFB counts, while longer magnetic separation time decreased the number of AFB observed per field in NCBA (Global correlation coefficient, 0.187, $p<0.001$ ). The long homogenization times are likely due to the high mucopurulence of the sputum samples, which is related to high viscosity and high cellular load. Highly viscous samples reduce the mobility of GMNPs in the matrix and the formation of GMNP-AFB complexes, which can have an influence on their magnetic separation.

\subsection{Supplementary Study Using Msm}

Figure 4A shows the capture efficiency (CE) of the GMNP in different concentrations of Msm. These were prepared in artificial sputum, magnetically extracted and plated on a MiddleBrook 7H10-ADC agar. The data shows that the $\mathrm{CE}$ decreases linearly with increasing bacterial concentration, 
from $95 \%$ at $10^{1} \mathrm{CFU} / \mathrm{mL}$ to $80 \%$ at $10^{5} \mathrm{CFU} / \mathrm{mL}$. This result supports the sputum data in Table 3 , where 1+ samples transform to 2+ using NCBA, since a lower bacterial concentration would result in a higher CE. Figure 4 also shows TEM images of corded Msm without GMNP (B) and with GMNP (C).

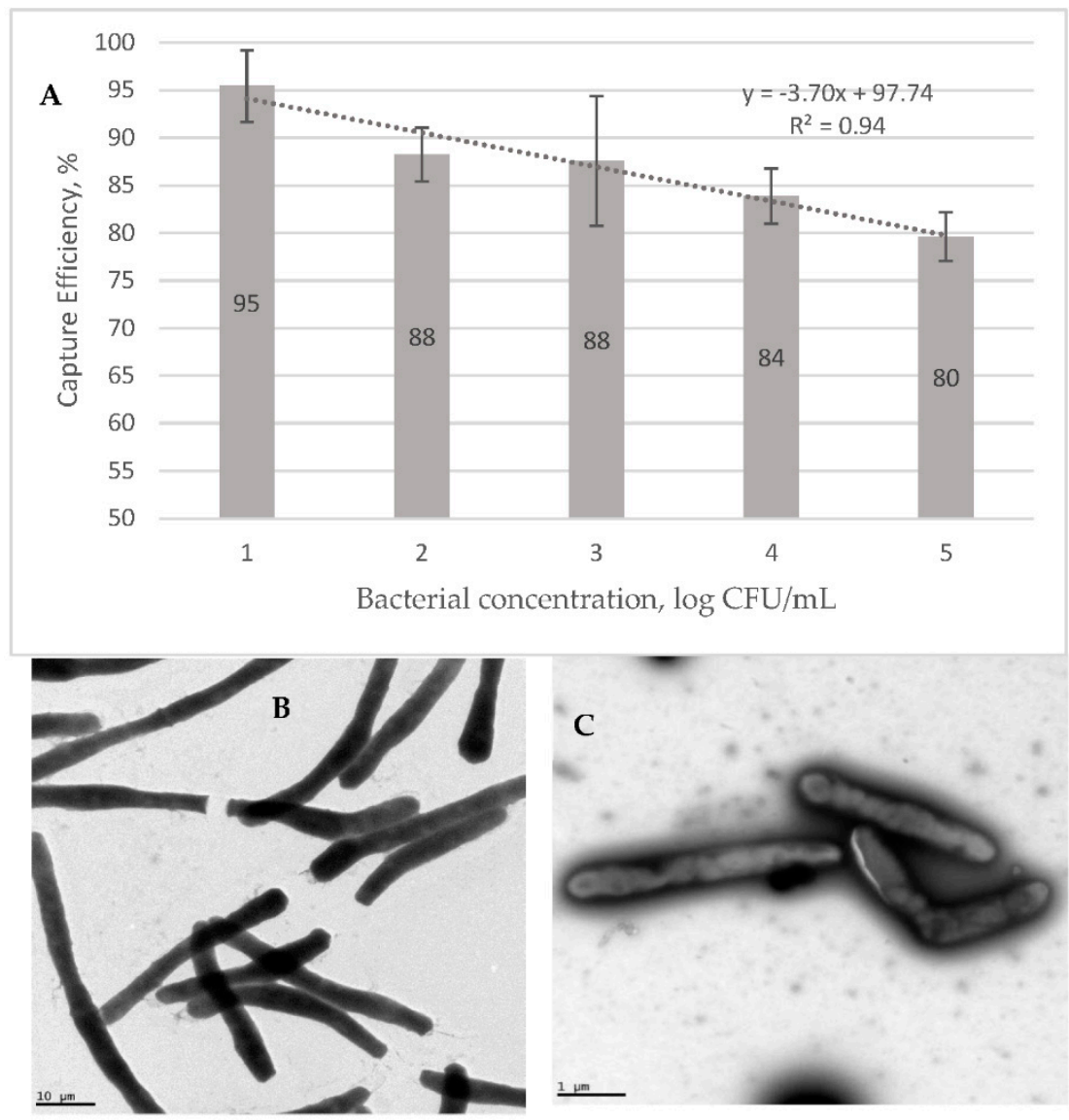

Figure 4. (A) Capture efficiency of GMNP for extracting Msm from artificial sputum. TEM images of (B) corded Msm without GMNP and (C) corded Msm with GMNP attached to specific site on the cell wall.

\section{Discussion}

SSM continues to be the main TB diagnostic method in medium and low income countries due to its affordability, simplicity in process and rapid results. However, its sensitivity ranges from 20-80\%, mainly due to the high AFB cell concentration that is required (5000-10,000 cells/mL). Different chemical and physical sputum processing methods have been studied to improve its sensitivity, but standardization of the treated samples is among major drawbacks [28]. The use of antibodies and peptides for bacterial extraction in a matrix is a common practice. In a study by Foddai et al. [29], magnetic beads coated with specific peptides yielded an $85-100 \%$ CE when used to separate Mycobacterium avium subsp. paratuberculosis from broth samples containing $10^{3}-10^{4} \mathrm{cfu} / \mathrm{mL}$ of the bacteria. Roberts and Hirst [30] used antibodies against Mycobacterium ulcerans to isolate the bacteria and yielded a $70-85 \%$ CE.

Studies evaluating nanoparticles synthesized with diverse materials have used spiked sputum samples from healthy donors and sophisticated equipment to detect whole mycobacterial cells [12,31-33]. Those studies have reported good detection of mycobacteria, but the assays are complex and expensive.

Sputum is a complex specimen consisting of linked mucin molecules, filamentous actin, cell debris, DNA, leukocytes, proteoglycans, inflammatory mediators and elastin fibers [34]. Embedded within this matrix are bacteria including $M t b$ in TB+ sputum. $M t b$ cells clump due to cording within the 
specimen, resulting in an unequal distribution. The efficient release of bacteria from sputum specimens requires a chemical and/or mechanical breakdown of the linked mucin and actin molecules [30]. For this study, a combination of $\mathrm{NaOH}(0.4 \%)$ and NALC $(0.025-4 \%)$ in a 1:1 ratio was explored for use in sputum digestion. The rationale for testing low and high concentrations of NALC was to determine if the solution would affect the overall performance of NCBA. Higher NALC concentration results in better liquefaction of the sputum and subsequently better extraction of AFB, however, that would also mean a higher cost since NALC is expensive. The assay is designed as a low-cost system for application in resource-limited environments. The results show that $0.4 \% \mathrm{NaOH} / 4 \% \mathrm{NALC}$ yielded the best performance, as indicated by the higher AFB count in NCBA, with an overall $143 \%$ increase over SSM (Table 1$)$. At a lower concentration of NALC $(0.025 \%)$, SSM resulted in higher AFB counts compared to NCBA, potentially due to the sputum not being fully liquefied and the GMNP-AFB complexes not being able to be released from the clumped matrix.

The use of a glycan bioreceptor on GMNP allows for simple and inexpensive capture of $\mathrm{Mtb}$ cells in the mucoid sputum samples without the use of expensive antibodies or aptamers. The Mtb cell envelope is particularly rich in complex carbohydrate-containing molecules, such as glycolipids (e.g., phosphatidyl-myo-inositol mannosides), lipoglycans (e.g., lipomannan and lipoarabinomannan), polysaccharides (e.g., $\alpha$-glucan) and glycoproteins. These mycobacterial carbohydrate molecules can bind with the glycan functionalized nanoparticles. Furthermore, cold storage is not required, allowing its application in conditions without refrigeration and electricity.

GMNP at $10 \mathrm{mg} / \mathrm{mL}$ was found to be the optimal amount to capture and concentrate AFB which resulted in the highest AFB count per field (Table 2, Figure 3). At a higher GMNP concentration $(20 \mathrm{mg} / \mathrm{mL})$, smears were difficult to observe due to high aggregation.

NALC at $1 \%$ and $2 \%$ resulted in $35 \%$ and $22 \%$ increases in AFB count, respectively. NALC at $4 \%$ resulted in a $143 \%$ increase in AFB count. If an input/output ratio is calculated, that is, \%NALC $\%$ AFB increase, $1 / 35$ and $4 / 143$ each equals to 0.028 while $2 / 22$ equals to 0.09 . This shows that increasing NALC concentration to homogenize the sputum sample correspondingly increases the AFB count, except for the $2 \%$ NALC that is more of an outlier. The experiments used $4 \%$ NALC as the upper value to minimize cost. It would be interesting to determine in future experiments the upper limit of NALC.

Also, longer homogenization time was correlated with longer magnetic separation. This could be due to the viscosity of the sputum which would then slow down the magnetic separation. Long magnetic separation had a negative effect on the AFB count. The longer the magnetic separation, the longer the exposure of AFB to the $\mathrm{NaOH} / \mathrm{NALC}$ homogenization solution, which would then increase the exposure of the sample to the decontamination effect of $\mathrm{NaOH}$, subsequently reducing the viability of the AFB.

\section{Determining GMNP's Capture Efficiency for Mycobacterial Cells}

Results from the GMNP extraction experiments using Msm showed that the CE ranged from an average of $80 \%$ to $95 \%$ for samples with AFB concentrations ranging from $10^{1} \mathrm{cfu} / \mathrm{mL}(\mathrm{n}=3)$ to $10^{3} \mathrm{cfu} / \mathrm{mL}$ and $10^{4} \mathrm{cfu} / \mathrm{mL}(\mathrm{n}=10$ each) (Figure $4 \mathrm{~A}$ ). The negative linear relationship between bacterial cell concentration and the CE indicates that NCBA would be highly useful in cases of low bacterial load, as in paucibacillary cases. These data show that as cells increase, CE decreases, potentially due to epitope competition. The lower the number of bacteria in the solution, the higher the ratio of nanoparticles is to bacterial epitopes, that is, more nanoparticles are available to bind and self-assemble on the surface of a bacterium. As the number of bacteria in the solution increases, the resulting higher number of bacterial epitopes compete with the available number of nanoparticles in the solution. Such a nanoparticle-based bacterial detection system would be highly sensitive at lower cell concentrations.

The physical interaction between GMNP and the Msm cell wall was also confirmed using TEM (Figure 4B,C). GMNPs attach to specific sites on the cellular surface through the carbohydrate-binding 
lectins on the bacterial surface. These data show that the GMNP interacts with the mycobacterial cell wall, forming a complex.

\section{Conclusions}

In summary, these results show that the NCBA technique has significant potential application in improving the diagnosis of paucibacillary TB cases (e.g., in immunocompromised individuals, children, drug-resistant TB, among others). Due to its ability to concentrate AFB, NCBA could improve one grade higher, making an initial case at $1+$ to become $2+$ with the assay, or go from "scant" to become $1+$ (Table 3). The assay uses only a simple magnet and does not require any major equipment, electricity or refrigeration, can be completed in 10-20 min and only costs $\$ 0.10$ per test. The glycan-based magnetic isolation method is novel and has advantages due to its affordability, long shelf-life, room-temperature storage and easy preparation. Thus, this system can be easily incorporated in clinical practice to enhance TB diagnosis, especially in low resource environments. It has been hypothesized that a rapid and universally accessible TB test with a sensitivity of $85 \%$ and specificity of $97 \%$ has the potential to save close to 400,000 adjusted lives annually, or $27 \%$ of the global TB deaths [35]. This NCBA technology satisfies the criteria well for rapid, affordable and universal access.

Future work will include determining the limit of detection (LOD) and comparing NCBA with cultures on solid media (7H11 Middlebrook), leading to sensitivity evaluation in paucibacillary cases. The assay will also use blinded samples in comparison with SSM, not only in sputum samples, but also in gastric samples from pediatric patients.

Author Contributions: E.C.A., A.G.-V., H.J.S.-P. conceived the study, participated in study design and coordinated the project. C.G.-M., S.G.M.-J., A.G.-V. performed experiments with human sputum. K.P., J.S., N.M., E.C.A., performed initial screening of MNPs with artificial sputum. A.B.-A., A.G.-B., L.J.-G., N.E-R. provided training and technical support and critically reviewed the manuscript. M.M., N.R.-S., C.G.-M., H.J.S.-P., E.C.A., A.G.-V. performed statistical analysis. A.G.-V., C.G.-M., E.C.A., H.J.S.-P. drafted the manuscript. E.C.A. finalized the manuscript and serves as the corresponding author. All authors read and approved the final version of the manuscript.

Funding: This research was funded by the W.K. Kellogg Foundation, Programa de Investigación Integrado de Tuberculosis PII-TB-SEPAR (grant number 058-2015), and by the Mexican National Council for Science and Technology [CONACyT, 402901 to C.G.M.].

Acknowledgments: The authors thank the staff of the Mycobacterial Laboratory, Highlands Region TB Program, Health Jurisdiction II, Chiapas, in assisting the screening of patients and in collecting sputum samples.

Conflicts of Interest: The authors declare no conflict of interest. They have no commercial or any association that might pose a conflict of interest with any entity or form. The funders had no role in the design of the study; in the collection, analyses, or interpretation of data; in the writing of the manuscript, or in the decision to publish the results.

\section{References}

1. WHO. Tuberculosis: Key Facts. Available online: http://www.who.int/news-room/fact-sheets/detail/ tuberculosis (accessed on 27 June 2018).

2. Parsons, L.M.; Somoskövi, Á.; Gutierrez, C.; Lee, E.; Paramasivan, C.N.; Abimiku, A.; Spector, S.; Roscigno, G.; Nkengasong, J. Laboratory diagnosis of Tuberculosis in resource-poor Countries: Challenges and Opportunities. Clin. Microbiol. Rev. 2011, 24, 314-350. [CrossRef] [PubMed]

3. American Thoracic Society. Diagnostic Standards and Classification of Tuberculosis in Adults and Children. This official statement of the American Thoracic Society and the Centers for Disease Control and Prevention was adopted by the ATS Board of Directors, July 1999. This statemen. Am. J. Respir. Crit. Care Med. 2000, 161, 1376-1395. [CrossRef]

4. Mase, S.R.; Ramsay, A.; Ng, V.; Henry, M.; Hopewell, P.C.; Cunningham, J.; Urbanczik, R.; Perkins, M.D.; Aziz, M.A.; Pai, M. Yield of serial sputum specimen examinations in the diagnosis of pulmonary tuberculosis: A systematic review. Int. J. Tuberc. Lung Dis. 2007, 11, 485-495.

5. WHO. Xpert MTB/RIF Assay for the Diagnosis of Pulmonary and Extrapulmonary TB in Adults and Children; Policy Update; WHO: Geneva, Switzerland, 2013. 
6. Ardizzoni, E.; Fajardo, E.; Saranchuk, P.; Casenghi, M.; Page, A.-L.; Varaine, F.; Kosack, C.S.; Hepple, P. Implementing the Xpert ${ }^{\circledR}$ MTB/RIF Diagnostic Test for Tuberculosis and Rifampicin Resistance: Outcomes and Lessons Learned in 18 Countries. PLoS ONE 2015, 10, e0144656. [CrossRef] [PubMed]

7. Ocheretina, O.; Byrt, E.; Mabou, M.-M.; Royal-Mardi, G.; Merveille, Y.-M.; Rouzier, V.; Fitzgerald, D.W.; Pape, J.W. False-positive rifampin resistant results with Xpert MTB/RIF version 4 assay in clinical samples with a low bacterial load. Diagn. Microbiol. Infect. Dis. 2016, 85, 53-55. [CrossRef]

8. Williamson, D.A.; Basu, I.; Bower, J.; Freeman, J.T.; Henderson, G.; Roberts, S.A. An evaluation of the Xpert MTB/RIF assay and detection of false-positive rifampicin resistance in Mycobacterium tuberculosis. Diagn. Microbiol. Infect. Dis. 2012, 74, 207-209. [CrossRef]

9. Torres-Chavolla, E.; Alocilja, E.C. Nanoparticle based DNA biosensor for tuberculosis detection using thermophilic helicase-dependent isothermal amplification. Biosens. Bioelectron. 2011, 26, 4614-4618. [CrossRef]

10. Gao, L.; He, X.; Ju, L.; Liu, X.; Li, F.; Cui, H. A label-free method for the detection of specific DNA sequences using gold nanoparticles bifunctionalized with a chemiluminescent reagent and a catalyst as signal reporters. Anal. Bioanal. Chem. 2016, 408, 8747-8754. [CrossRef]

11. He, F.; Xiong, Y.; Liu, J.; Tong, F.; Yan, D. Construction of Au-IDE/CFP10-ESAT6 aptamer/DNA-AuNPs MSPQC for rapid detection of Mycobacterium tuberculosis. Biosens. Bioelectron. 2016, 77, 799-804. [CrossRef]

12. Qin, D.; He, X.; Wang, K.; Zhao, X.J.; Tan, W.; Chen, J. Fluorescent Nanoparticle-Based Indirect Immunofluorescence Microscopy for Detection of Mycobacterium tuberculosis. J. Biomed. Biotechnol. 2007, 2007, 89364. [CrossRef]

13. Qin, D.; He, X.; Wang, K.; Tan, W. Using fluorescent nanoparticles and SYBR Green I based two-color flow cytometry to determine Mycobacterium tuberculosis avoiding false positives. Biosens. Bioelectron. 2008, 24, 626-631. [CrossRef] [PubMed]

14. Ekrami, A.; Samarbaf-Zadeh, A.R.; Khosravi, A.; Zargar, B.; Alavi, M.; Amin, M.; Kiasat, A. Validity of bioconjugated silica nanoparticles in comparison with direct smear, culture, and polymerase chain reaction for detection of Mycobacterium tuberculosis in sputum specimens. Int. J. Nanomed. 2011, 6, 2729-2735. [CrossRef] [PubMed]

15. Loewenberg, S. Chiapas, Mexico: From Tuberculosis to Insurgent Bureaucracy. Available online: https: / pulitzercenter.org/reporting/chiapas-mexico-tuberculosis-insurgent-bureaucracy (accessed on 27 June 2018).

16. Sánchez-Pérez, H.J.; Gómez-velasco, A.; Leal, G.; Bencomo-Alerm, A.; Romero-Sandoval, N.; Martín-Mateo, M. Tuberculosis (TB) and Human Rights in Chiapas, Mexico. In Tuberculosis-Expanding Knowledge; Ribón, W., Ed.; Intech Open: London, UK, 2015; pp. 1-42.

17. Nájera-Ortiz, J.C.; Sánchez-Pérez, H.J.; Ochoa-Díaz, H.; Arana-Cedeño, M.; Lezama, M.; Mateo, M.M. Demographic, health services and socio-economic factors associated with pulmonary tuberculosis mortality in Los Altos Region of Chiapas, Mexico. Int. J. Epidemiol. 2008, 37, 786-795. [CrossRef] [PubMed]

18. Sánchez-Pérez, H.J.; Hernán, M.A.; Díaz, S.H.; Jansá, J.M.; Halperin, D.; Ascherio, A. Detection of Pulmonary Tuberculosis in Chiapas, Mexico. Ann. Epidemiol. 2002, 12, 166-172. [CrossRef]

19. Meza-Palmeros, J.A.; Sánchez-Pérez, H.J.; Freyermuth-Enciso, G.; Sánchez-Ramírez, G. El gradiente socioeconómico de la mortalidad por tuberculosis en México (2004-2008). Población y Salud en Mesoamérica 2013, 10, 5-16. [CrossRef]

20. Sánchez-Pérez, H.J.; Díaz-Vázquez, A.; Nájera-Ortiz, J.C.; Balandrano, S.; Martín-Mateo, M. Multidrug-resistant pulmonary tuberculosis in Los Altos, Selva and Norte regions, Chiapas, Mexico. Int. J. Tuberc. Lung Dis. 2010, 14, 34-39.

21. Loewenberg, S. Tackling tuberculosis in southern Mexico. Lancet 2010, 375, 1768-1769. [CrossRef]

22. Nájera-Ortiz, J.C.; Sánchez-Pérez,H.J.; Ochoa-Díaz-López, H.; Leal-Fernández, G.; Navarro-Giné, A. The Poor Survival among Pulmonary Tuberculosis Patients in Chiapas, Mexico: The Case of Los Altos Region. Tuberc. Res. Treat. 2012, 2012, 708423. [CrossRef]

23. Kik, S.V.; Denkinger, C.M.; Chedore, P.; Pai, M. Replacing smear microscopy for the diagnosis of tuberculosis: What is the market potential? Eur. Respir. J. 2014, 43, 1793-1796. [CrossRef]

24. World Health Organization; International Union Against Tuberculosis and Lung Disease (IUATLD). Technical guide for sputum examination for tuberculosis by direct smear microscopy in low income countries. Int. J. Tuberc Lung Dis. 2001, 5, 213-215. 
25. Mohan, A.; Padiadpu, J.; Baloni, P.; Chandra, N. Complete Genome Sequences of a Mycobacterium smegmatis Laboratory Strain (MC2 155) and Isoniazid-Resistant (4XR1/R2) Mutant Strains. Genome Announc. $2015,3$. [CrossRef]

26. Tyagi, J.S.; Sharma, D. Mycobacterium smegmatis and tuberculosis. Trends Microbiol. 2002, 10, 68-69. [CrossRef]

27. Yamada, H.; Mitarai, S.; Aguiman, L.; Matsumoto, H.; Fujiki, A. Preparation of mycobacteria-containing artificial sputum for TB panel testing and microscopy of sputum smears. Int. J. Tuberc. Lung Dis. 2006, 10, 899-905. [PubMed]

28. Steingart, K.R.; Henry, M.; Ng, V.; Hopewell, P.C.; Ramsay, A.; Cunningham, J.; Urbanczik, R.; Perkins, M.; Aziz, M.A.; Pai, M. Fluorescence versus conventional sputum smear microscopy for tuberculosis: A systematic review. Lancet Infect. Dis. 2006, 6, 570-581. [CrossRef]

29. Foddai, A.; Elliott, C.T.; Grant, I.R. Maximizing capture efficiency and specificity of magnetic separation for Mycobacterium avium subsp. paratuberculosis cells. Appl. Environ. Microbiol. 2010, 76, 7550-7558. [CrossRef] [PubMed]

30. Roberts, B.; Hirst, R. Immunomagnetic separation and PCR for detection of Mycobacterium ulcerans. J. Clin. Microbiol. 1997, 35, 2709-2711.

31. Lee, H.; Yoon, T.; Weissleder, R. Ultrasensitive Detection of Bacteria Using Core-Shell Nanoparticles and an NMR-Filter System. Angew. Chem. 2009, 121, 5657-5660. [CrossRef]

32. Yang, H.; Qin, L.; Wang, Y.; Zhang, B.; Liu, Z.; Ma, H.; Lu, J.; Huang, X.; Shi, D.; Hu, Z. Detection of Mycobacterium tuberculosis based on H37Rv binding peptides using surface functionalized magnetic microspheres coupled with quantum dots-A nano detection method for Mycobacterium tuberculosis. Int. J. Nanomed. 2014, 10, 77-88. [CrossRef]

33. Liandris, E.; Gazouli, M.; Andreadou, M.; Sechi, L.A.; Rosu, V.; Ikonomopoulos, J. Detection of pathogenic mycobacteria based on functionalized quantum dots coupled with immunomagnetic separation. PLoS ONE 2011, 6, e20026. [CrossRef]

34. Allen, V.; Nicol, M.P.; Tow, L.A. Sputum processing prior to Mycobacterium tuberculosis detection by culture or nucleic acid amplification testing: A narrative review. Res. Rev. J. Microbiol. Biotechnol. 2016, 5, 120-130.

35. Desikan, P. Sputum smear microscopy in tuberculosis: Is it still relevant? Indian J. Med. Res. 2013, 137, $442-444$. [PubMed] 